\title{
Spectrophotometric Estimation of Flutamide in Pure and in Pharmaceutical Preparations
}

\author{
Hemavathi Nagaraju Deepakumari and Hosakere Doddarevanna Revanasiddappa \\ Department of Chemistry, University of Mysore, Manasagangotri, Mysore 570006, India \\ Correspondence should be addressed to Hosakere Doddarevanna Revanasiddappa, hdrevanasiddappa@yahoo.com
}

Received 9 October 2012; Accepted 27 October 2012

Academic Editors: T. Stafilov and Y. Ueno

Copyright ( $\odot 2012$ H. N. Deepakumari and H. D. Revanasiddappa. This is an open access article distributed under the Creative Commons Attribution License, which permits unrestricted use, distribution, and reproduction in any medium, provided the original work is properly cited.

\begin{abstract}
Three simple, rapid, precise, sensitive, and accurate visible spectrophotometric methods (A, B, and C) are described for the estimation of flutamide in both pure and pharmaceutical preparations. They are based on the diazotization of reduced flutamide (FA) with nitrous acid followed by coupling with acetyl acetone (method A), citrazinic acid (method B), and 8-hydroxyquinoline (method C) to form colored azo dyes, exhibiting absorption maxima $\left(\lambda_{\max }\right)$ at 410,440 and $500 \mathrm{~nm}$, for methods A, B, and C, respectively. Linear concentration range was of $0.5-12,0.5-10$, and $0.3-10 \mu \mathrm{g} / \mathrm{mL}$ for methods $\mathrm{A}, \mathrm{B}$, and $\mathrm{C}$, respectively, and the corresponding molar absorptivity values are $2.23 \times 10^{4}, 2.04 \times 10^{4}$, and $1.35 \times 10^{4} \mathrm{~L} \mathrm{~mol}^{-1} \mathrm{~cm}^{-1}$. The correlation coefficients for FA are $0.9988,0.9976$, and 0.9975 for methods A, B, and C, respectively. All variables were optimized, and the results were statistically compared with those of a literature method by employing Student's $t$-test and $F$-test. No interference was observed from common adjuvants normally added to the tablets. The relative standard deviations $(n=5)$ for FA in all the three methods in the tablets are always less than $3 \%$.
\end{abstract}

\section{Introduction}

Flutamide (FA), chemically known as 2-methyl-N-[4-nitro3 -(trifluoromethyl)phenyl]-propanamide (Figure 1), is a potent nonsteroidal antiandrogen drug primarily used to treat prostatic cancer [1-3]. FA competes with testosterone and its powerful metabolite, dihydrotestosterone (DHT) for binding to androgen receptors in the prostate gland thereby, and it inhibits the prostate cancer cells to grow. Flutamide has been largely replaced by a newer member of this class, bicalutamide, due to a better side-effect profile. Flutamide may also be used to treat excess androgen levels in womenespecially those with polycystic ovarian syndrome (PCOS) [4]. This drug and its primary hydroxy metabolite decrease metabolism of C- 19 steroids by the cytochrome P-450 system at the target cells in the secondary sex organ [5]. The official method for its determination is liquid chromatography reported in European Pharmacopoeia [6].

Different analytical methods for the quantitative determination of $\mathrm{FA}$ in pure form, in pharmaceutical preparations and in biological fluids, including HPLC [7-9], electrochemical reduction [10], stripping voltammetry [11], spectrofluorometry [12], and spectrophotometry [13-15] have been reported. The reported chromatographic techniques [7-9] require expensive experimental setup and are not affordable in every laboratory for routine analysis. The stripping voltammetric technique [11] requires sophisticated instrumentation, and involvement of scrupulous experimental conditions, whereas the reported spectrfluorimetric method [12] is less sensitive, and the cited spectrophotometric methods have some disadvantages such as less sensitivity, poorer selectivity [13, 15], and requires extraction step [14] for FA determination. Thus, there is a need to develop sensitive, accurate, and cost-effective methods for its determination.

The present paper proposes three simple, sensitive, and inexpensive methods which allow a quick determination of FA in pure form and in dosage forms. The developed three visible spectrophotometric methods are based on diazocoupling reactions using acetyl acetone (AA), citrazinic acid (CZA), and 8-hydroxyquinoline (HQ) as the coupling agents. 
<smiles>CC(C)C(=O)Nc1ccc([N+](=O)[O-])c(C(F)(F)F)c1</smiles>

FIGURE 1: Structure of flutamide.

\section{Materials and Methods}

2.1. Apparatus. All absorbance measurements were performed using a Systronics Model 166 digital spectrophotometer provided with $1 \mathrm{~cm}$ matched quartz cells.

2.2. Reagents and Standards. Analytical reagent grade chemicals were used, and double distilled water was used throughout the experiment to prepare all solutions.

(i) Standard drug solution: the pharmaceutical grade FA, certified to be $99.99 \%$ pure, was received from Cipla Ltd., India, as a gift sample and was used as received. Accurately $10 \mathrm{mg}$ of FA was transferred into a $100 \mathrm{~mL}$ beaker, and it was dissolved in $20 \mathrm{~mL}$ methanol. To this, $5 \mathrm{~mL} 4 \mathrm{~N}$ hydrochloric acid and $1 \mathrm{~g}$ of zinc dust were added and shaken thoroughly for about 15 min and then diluted up to the mark with water in a $100 \mathrm{~mL}$-calibrated flask $(100 \mu \mathrm{g} / \mathrm{mL})$ and filter through Whatman No. 41 filter paper. Working solutions were prepared as required by dilution.

(ii) Acetyl acetone (AA) (5\% w/v) was prepared by diluting $5.1 \mathrm{~mL}$ of AA (BDH chemicals, Poole, England) in $100 \mathrm{~mL}$ of methanol.

(iii) Citrazinic acid (CZA) $(0.1 \% \mathrm{w} / \mathrm{v})$ was prepared by dissolving $0.1 \mathrm{~g}$ of the citrazinic acid (Fluka, Switzerland) in $2 \mathrm{~mL} 4 \mathrm{M}$ sodium hydroxide and diluting to $100 \mathrm{~mL}$ with distilled water.

(iv) 8-hydroxyquinoline (Oxine) $(0.2 \% \mathrm{w} / \mathrm{v})$ was prepared by dissolving $0.2 \mathrm{~g}$ oxine (Indian Drugs and Pharmaceuticals Ltd., Hyderabad, India) in $100 \mathrm{~mL}$ of distilled water containing $3 \mathrm{~g}$ of sodium hydroxide.

(v) Others: aqueous solutions of sodium nitrite (Merck) $(0.1 \%)$, sulphamic acid (Qualigens) $(3.0 \% \mathrm{w} / \mathrm{v})$, and sodium hydroxide (Merck) (4 M) were used.

\subsection{General procedures}

2.3.1. Method A. Aliquot of reduced FA solutions ranging from 0 to $12 \mu \mathrm{g} / \mathrm{mL}$ was transferred into a series of $10 \mathrm{~mL}$ volumetric flasks. To each flask, $1 \mathrm{~mL}$ sodium nitrite $(0.1 \% \mathrm{w} / \mathrm{v})$ and $1 \mathrm{~mL}$ of $1 \mathrm{M}$ hydrochloric acid were added. After $3 \mathrm{~min}$, $1 \mathrm{~mL}$ of sulfamic acid $(3 \% \mathrm{w} / \mathrm{v})$ was added to each flask. Then, $2 \mathrm{~mL}$ each of the acetyl acetone $(5 \% \mathrm{w} / \mathrm{v})$ and $4 \mathrm{M}$ sodium hydroxide were added. The contents were made up to the mark with distilled water and mixed well. After $10 \mathrm{~min}$, the absorbance of the yellow-colored azo dye was measured at $410 \mathrm{~nm}$ against the reagent blank.

2.3.2. Method B. Varying aliquots of reduced FA solution ranging from 0 to $10 \mu \mathrm{g} / \mathrm{mL}$ were transferred into a series of $10 \mathrm{~mL}$ volumetric flasks. To each flask, $1.5 \mathrm{~mL}$ of the sodium nitrite $(0.1 \% \mathrm{w} / \mathrm{v})$ and $1 \mathrm{~mL}$ of $1 \mathrm{M}$ hydrochloric acid were added. After $3 \mathrm{~min}, 1 \mathrm{~mL}$ of sulfamic acid (3\% w/v) and then $2 \mathrm{~mL}$ each of the citrazinic acid $(0.1 \% \mathrm{w} / \mathrm{v})$ and $4 \mathrm{M}$ sodium hydroxide were added. The volumes were made up to the mark with distilled water and mixed well. The absorbance of the colored azo dye was measured at $440 \mathrm{~nm}$ against the reagent blank ten minutes later.

2.3.3. Method $C$. An aliquot of reduced FA solution containing $0-10 \mu \mathrm{g} / \mathrm{mL}$ of FA was transferred into a series of $10 \mathrm{~mL}$ calibrated flasks. To this solution was added $1.5 \mathrm{~mL}$ of $0.1 \%$ sodium nitrite, and the acidity was adjusted with $1.0 \mathrm{~mL}$ of $1 \mathrm{M}$ hydrochloric acid. The solution was shaken thoroughly for 3 min to allow diazotization reaction to go to completion. A volume of $2 \mathrm{~mL}$ of $3 \%$ sulfamic acid was added to each flask. Then, volumes of $1 \mathrm{~mL}$ of 8 -hydroxyquinoline $(0.2 \%)$ and $2 \mathrm{~mL}$ of $4 \mathrm{M}$ sodium hydroxide were added, and the contents were diluted to the mark with distilled water and mixed well. The absorbance of the colored azo dye was measured at $500 \mathrm{~nm}$ against the reagent blank after $10 \mathrm{~min}$.

The amount of FA present in the pharmaceutical sample was computed from the concurrent calibration curves.

2.4. Procedure for Pharmaceutical Preparation. Five tablets were weighed accurately and ground into a fine powder. Tablets powder equivalent to $10 \mathrm{mg}$ of the FA was accurately weighed and transferred into a $100 \mathrm{~mL}$ beaker and it was dissolved in $20 \mathrm{~mL}$ methanol. To this, $5 \mathrm{~mL} 4 \mathrm{~N}$ hydrochloric acid and $1 \mathrm{~g}$ of zinc dust were added and stirred thoroughly for about $30 \mathrm{~min}$. The contents were diluted with $50 \mathrm{~mL}$ distilled water and filtered using Whatman No. 41 filter paper. The filtrate was received into a $100 \mathrm{~mL}$ volumetric flask and it was made up to the mark with water. Appropriate aliquots of the drug solution were taken and the proposed methods (A, B and C) were followed for analysis of the drug content.

\section{Results and Discussion}

The methods that involve the aromatic amino group in reduced flutamide undergo diazotization with nitrous acid, and resulting diazonium ion was coupled with acetyl acetone (Method A), citrazinic acid (Method B), and 8-hydroxyquinoline (Method C) to form colored azo-dyes and exhibiting absorption maxima $\left(\lambda_{\max }\right)$ at 410,440 and $500 \mathrm{~nm}$, respectively for methods $\mathrm{A}, \mathrm{B}$, and $\mathrm{C}$ (Figure 2 ). The formed colored azo dyes are stable for a period of $2 \mathrm{~h}$ in each method.

Two steps are involved in the reaction that produces the colored azo dyes. In the first step, reduced FA is treated with nitrite solution in hydrochloric acid medium and undergoes diazotization to give diazonium ion. In the second step, the diazonium ion is coupled with the coupling agent's acetyl 


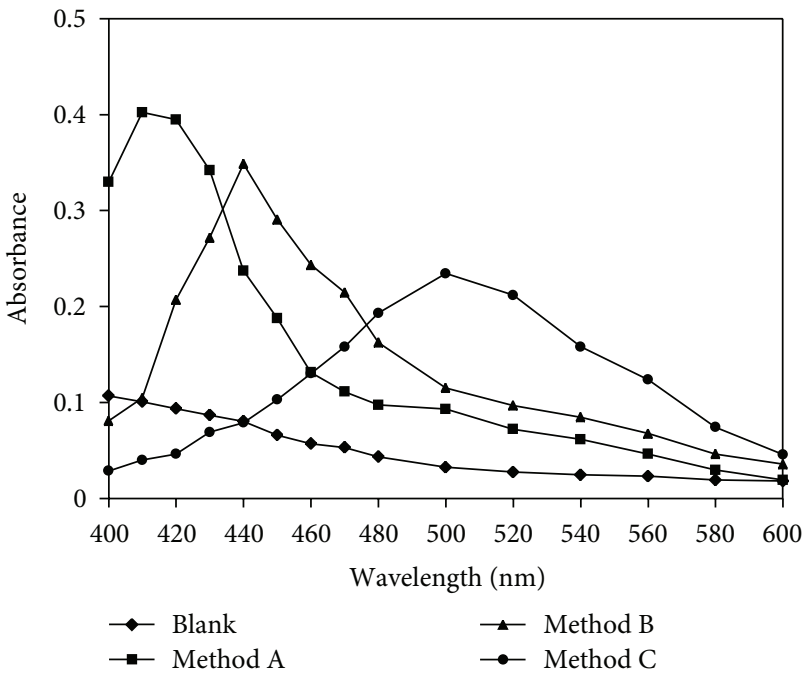

Figure 2: Absorption spectra for $5 \mu \mathrm{g} / \mathrm{mL}$ FA (methods A-C).

acetone (Method A), citrazinic acid (Method B), and 8hydroxyquinoline (Method C) to form colored azo dyes in an alkaline medium. The reaction pathways of all the methods are shown in Scheme 1.

\subsection{Optimization of Experimental Parameters}

3.1.1. Effects of Reagent Concentrations. The effect of reagent concentrations such as AA, CZA, and HQ on the absorbance was investigated, and the results indicated that the constant absorbance readings were obtained in the range $1.0-4 \mathrm{~mL}$ of $5 \% \mathrm{AA}, 1.0-4.0 \mathrm{~mL}$ of $0.1 \% \mathrm{CZA}$, and $0.5-3.0 \mathrm{~mL}$ of $0.2 \%$ 8-hydroxyquinoline, respectively. Therefore, a volume of $2.0 \mathrm{~mL}$ each of $5 \%$ AA for method A, $0.1 \%$ CZA (method $\mathrm{B})$, and $1.0 \mathrm{~mL}$ of $0.2 \%$ oxine (method $\mathrm{C}$ ) were selected and thus used in all subsequent experimental work.

3.1.2. Effect of Sodium Hydroxide. In order to develop a quantitative method based on this reaction, study was conducted to determine the most effective and optimum alkali concentration to be used. A volume of $2 \mathrm{~mL}$ of $4 \mathrm{M}$ sodium hydroxide for all the methods $\mathrm{A}, \mathrm{B}$, and $\mathrm{C}$ were found to be sufficient for maximum color development.

3.1.3. Effect of Reaction Time and Stability of the Azo Dye. The colored azo dyes developed rapidly after the addition of the reagents and attained maximum intensity after about $10 \mathrm{~min}$ at room temperature (methods A-C). Stability study of the azo dye was carried out by measuring the absorbance values at time intervals of $10 \mathrm{~min}$. Under the described experimental conditions, the developed color was stable for a period of more than $2 \mathrm{~h}$ in all the three methods.
TABle 1: Optical characteristics and precision.

\begin{tabular}{|c|c|c|c|}
\hline Parameter & Method A & Method B & Method C \\
\hline$\lambda_{\max } \mathrm{nm}$ & 410 & 440 & 500 \\
\hline Linear range $(\mu \mathrm{g} / \mathrm{mL})$ & $0.5-12$ & $0.5-10$ & $0.3-10$ \\
\hline $\begin{array}{l}\text { Molar absorptivity }(\varepsilon) \text {, } \\
(\mathrm{L} / \mathrm{mol} / \mathrm{cm})\end{array}$ & $2.23 \times 10^{4}$ & $2.04 \times 10^{4}$ & $1.35 \times 10^{4}$ \\
\hline Sandell sensitivity $\left(\mu \mathrm{g} \mathrm{cm}^{-2}\right)$ & 0.0281 & 0.0136 & 0.0205 \\
\hline Intercept $(a)$ & 0.0124 & 0.0179 & 0.0116 \\
\hline Slope $(b)$ & 0.0734 & 0.0669 & 0.0439 \\
\hline Correlation coefficient $(r)$ & 0.9988 & 0.9976 & 0.9975 \\
\hline$S_{a}$ & 0.0182 & 0.0248 & 0.0167 \\
\hline$S_{b}$ & 0.0012 & 0.0027 & 0.0018 \\
\hline LOQ $(\mu \mathrm{g} / \mathrm{mL})$ & 0.1197 & 0.1047 & 0.2587 \\
\hline $\operatorname{LOD}(\mu \mathrm{g} / \mathrm{mL})$ & 0.0395 & 0.0345 & 0.0854 \\
\hline
\end{tabular}

\subsection{Method Validation}

3.2.1. Linearty. A linear correlation was found between the absorbance at respective wavelengths and concentrations of FA in the ranges as given in Table 1. The regression analysis using method of least squares was made for the slope $(b)$, intercept $(a)$, and correlation $(r)$, obtained from different concentrations, and the results are summarized in Table 1. The optical characteristics such as absorption maxima, Beer's law limit, molar absorptivity, and Sandell's sensitivity, the limits of detection and quantitation calculated as per the current ICH [16] guidelines, are compiled in Table 1.

3.2.2. Sensitivity. The limit of detection (LOD) and limit of quantitation (LOQ), for the proposed methods, were evaluated as per ICH guidelines using the following formula:

$$
\mathrm{LOD}=\frac{3.3 \times \sigma}{s}, \quad \mathrm{LOQ}=\frac{10 \times \sigma}{s},
$$

where $\sigma$ is the standard deviation of replicate determination values under the same conditions as for the sample analysis in the absence of the analyte, and $s$ is the slope of the calibration graph. The high values of molar absorptivity $(\varepsilon)$ and low values of Sandell's sensitivity and LOD in both the methods indicate the high sensitivity of the proposed methods (Table 1).

3.2.3. Intraday and Interday Accuracy and Precision. Further the accuracy and precision (intra-day) of the proposed methods were evaluated by replicate analysis $(n=5)$ of calibration standards at three different concentration levels in the same day. Accuracy and precision of interday were measured by performing the calibration standards at three cited concentrations on five consecutive days. Both precision and accuracy were based on the calculated percent relative standard deviation (RSD, \%) and percent relative error (RE, \%) of found concentration compared to the theoretical one, 
TABLE 2: Evaluation of intra-day and inter-day accuracy and precision results.

\begin{tabular}{|c|c|c|c|c|c|c|c|}
\hline \multirow{2}{*}{ Method } & \multirow{2}{*}{ FA taken, $\mu \mathrm{g} / \mathrm{mL}$} & \multicolumn{3}{|c|}{ Intra-day ${ }^{\mathrm{a}}$} & \multicolumn{3}{|c|}{ Inter-day ${ }^{\mathrm{b}}$} \\
\hline & & FA found ${ }^{\mathrm{c}}, \mu \mathrm{g} / \mathrm{mL}$ & Precision $^{\mathrm{d}}$ & Accuracy $^{\mathrm{e}}$ & FA found ${ }^{c}, \mu \mathrm{g} / \mathrm{mL}$ & Precision $^{\mathrm{d}}$ & Accuracy $^{\circ}$ \\
\hline \multirow{3}{*}{ A } & 2 & 1.98 & 1.61 & 0.93 & 1.97 & 2.32 & 1.36 \\
\hline & 6 & 5.96 & 0.75 & 0.69 & 5.89 & 1.32 & 1.81 \\
\hline & 10 & 10.02 & 1.13 & -0.18 & 9.89 & 2.13 & 1.04 \\
\hline \multirow{3}{*}{ B } & 2 & 1.99 & 0.61 & 0.80 & 1.96 & 2.06 & 1.81 \\
\hline & 4 & 3.97 & 0.87 & 0.73 & 3.92 & 0.94 & 1.96 \\
\hline & 8 & 7.90 & 1.25 & 2.17 & 8.10 & 2.75 & 1.23 \\
\hline \multirow{3}{*}{$\mathrm{C}$} & 2 & 1.98 & 2.56 & 0.90 & 2.04 & 1.26 & 1.98 \\
\hline & 4 & 3.98 & 1.00 & 0.54 & 3.92 & 1.25 & 1.96 \\
\hline & 8 & 7.89 & 0.37 & 1.36 & 7.87 & 2.22 & 1.63 \\
\hline
\end{tabular}

${ }^{\mathrm{a}}$ Mean value of five determinations; ${ }^{\mathrm{b}}$ Mean value of five determinations; ${ }^{\mathrm{c}}$ Mean value of three determinations; ${ }^{\mathrm{d}}$ Relative standard deviation (\%); ${ }^{\mathrm{e}}$ Bias $\%$ : (found - taken/taken) $\times 100$.

TABLE 3: Results of determination of FA in tablets and statistical comparison with the reference method.

\begin{tabular}{|c|c|c|c|c|c|}
\hline \multirow{2}{*}{ Tablet brand name } & \multirow{2}{*}{$\begin{array}{c}\text { Nominal amount } \\
\text { mg per tablet }\end{array}$} & \multicolumn{4}{|c|}{ Found ${ }^{* *}(\%$ of nominal amount $\pm \mathrm{SD})$} \\
\hline & & $\begin{array}{c}\text { Reference } \\
\text { method [13] }\end{array}$ & Method A & Method B & Method C \\
\hline CYTOMID $^{\mathrm{a}}$ & $250 \mathrm{mg}$ & $100.22 \pm 0.62$ & $\begin{array}{c}100.31 \pm 0.406 \\
t=0.136 \\
F=2.34\end{array}$ & $\begin{array}{c}101.02 \pm 0.398 \\
t=1.247 \\
F=2.43\end{array}$ & $\begin{array}{c}100.46 \pm 0.382 \\
t=0.689 \\
F=3.05\end{array}$ \\
\hline DROGENIL ${ }^{\mathrm{b}}$ & $250 \mathrm{mg}$ & $100.22 \pm 0.62$ & $\begin{array}{c}99.64 \pm 0.317 \\
t=0.971 \\
F=3.83\end{array}$ & $\begin{array}{c}100.87 \pm 0.288 \\
t=1.134 \\
F=4.63\end{array}$ & $\begin{array}{c}100.60 \pm 0.399 \\
t=0.591 \\
F=2.42\end{array}$ \\
\hline
\end{tabular}

Marketed by: ${ }^{\mathrm{a} C i p l a ~(P v t) ~ L t d ; ~}{ }^{\text {F Fulford. }}$

$* *$ Mean value of five determinations.

Tabulated $t$ and $F$-values at $95 \%$ confidence level are 2.77 and 6.39, respectively.

respectively (Table 2 ). The result shows that these methods have reasonable precision (Table 2 ).

3.2.4. Application to the Tablet Analysis. The developed methods (A-C) were applied to the determination of FA in tablet solutions at three different concentrations. The results were compared with those of the reported method [13]. Statistical analysis of the results using the Student's- $t$ and Ftests revealed no significant difference between the reported method and the official method at the 95\% confidence level with respect to accuracy and precision (Table 3 ).

3.2.5. Recovery. The accuracy and reliability of the methods developed were further ascertained by recovery experiments performed on synthetic mixtures of FA with several excipients such as talc $(20 \mathrm{mg})$, dextrose $(10 \mathrm{mg})$, sodium alginate (10 mg), starch (15 mg), acacia (20 mg), and magnesium stearate $(10 \mathrm{mg})$ by the proposed methods and recoveries obtained by each method, were in the range 98.5 to $102.5 \%$ $(n=5)$.

The accuracy and precision of the proposed methods were further ascertained by performing recovery studies by standard addition technique. Preanalyzed tablet powder was spiked with pure drug at three different concentrations, and the total was found by the proposed methods. Each determination was repeated three times. The recovery of the pure drug added was quantitative and revealed that coformulated substances did not interfere in the determination. The results of recovery study are compiled in Table 4 .

\section{Conclusions}

The developed visible spectrophotometric methods are sensitive, accurate, precise, reproducible, and economical and can be successfully applied for the determination of flutamide in bulk and in pharmaceutical dosage forms. The methods developed do not require any tedious extraction or heating procedures. Furthermore, no expensive or toxic reagents or organic solvents are required. The methods developed are rapid and do not involve any stringent experimental conditions, which influence the sensitivity and reliability of the methods. The most striking advantage of the spectrophotometric methods developed is that diazotization was carried out at room temperature, and cooling to $0-$ $5^{\circ} \mathrm{C}$ was not necessary. The methods are unaffected by slight variations in the experimental conditions such as basicity, reagent concentrations, and temperature. Hence, the method developed could be applied for the determination of FA in routine quality control laboratories. 


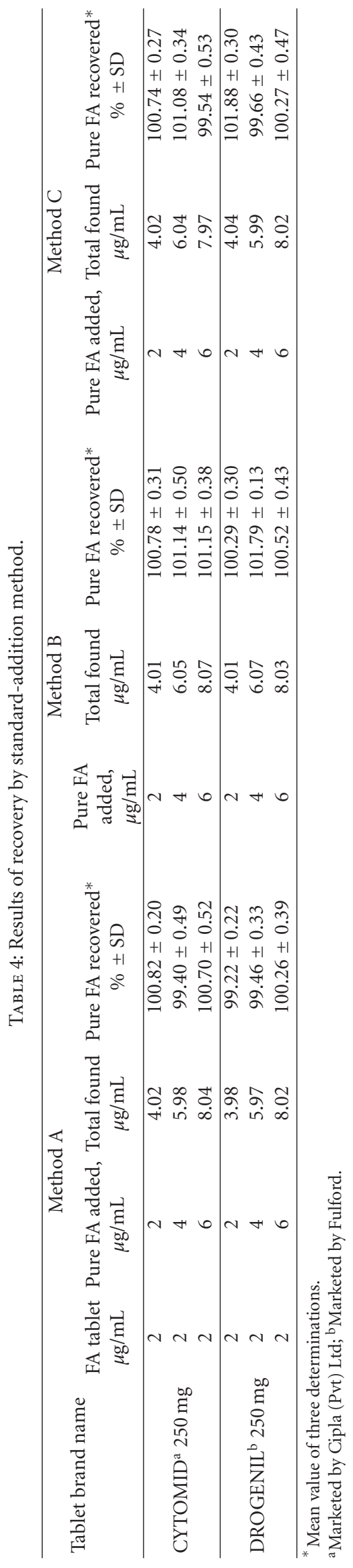


<smiles>CC(C)C(=O)Nc1ccc([N+](=O)[O-])c(C(F)(F)F)c1</smiles>

FA<smiles>CC(C)C(=O)Nc1ccc(N)c(C(F)(F)F)c1</smiles>

Reduced FA<smiles>CC(C)C(=O)Nc1ccc([N+]#N)c(C(F)(F)F)c1</smiles>

Diazonium ion<smiles>CC(=O)C(N=Nc1ccc(NC(=O)C(C)C)cc1C(F)(F)F)C(C)=O</smiles>

Scheme 1: Proposed reaction scheme for FA.

\section{Acknowledgments}

The authors are grateful to Cipla, Ltd., India for the generous supply of pure drug sample. H. N. Deepakumari is thankful to the University of Mysore, Mysore, India, for providing necessary facilities.

\section{References}

[1] R. N. Brogden and P. Chrisp, "Flutamide. A review of its pharmacodynamic and pharmacokinetic properties, and therapeutic use in advanced prostatic cancer," Drugs \& Aging, vol. 1, no. 2, pp. 104-115, 1991.

[2] D. G. McLeod, “Antiandrogenic drugs," Cancer, vol. 71, no. 3, pp. 1046-1049, 1993.

[3] Australian Pharmaceutical Formulary and Handbook, Pharmaceutical Society of Australia, Melrose Park, Australia, 19th edition, 2004.

[4] http://www.nhs.uk/Conditions/Polycystic-ovariansyndrome/ Pages/Treatment.aspx.

[5] A. Osol and J. E. Hoover, Remington's Pharmaceutical Sciences, Marck Publishing Company, Easton, Pa, USA, 18th edition, 1996.

[6] European Pharmacopoeia, vol. 1, 5th edition, 2005.

[7] I. Niopas and A. C. Daftsios, "Determination of 2-hydroxyflutamide in human plasma by high-performance liquid chromatography and its application to pharmacokinetic studies," Journal of Chromatography B, vol. 759, no. 1, pp. 179-183, 2001.
[8] A. Anton Smith, R. Manavalan, K. Kannan, and N. Rajendiran, "Improved liquid chromatographic method for the determination of flutamide in pharmaceutical formulation," International Journal of PharmTech Research, vol. 1, no. 2, pp. 360$364,2009$.

[9] H. R. N. Salgado, M. De Menezes, and M. P. B. Storti, "Determination of flutamide in tablets by high-performance liquid chromatography," Acta Farmaceutica Bonaerense, vol. 24, no. 2, pp. 246-249, 2005.

[10] G. V. Subba Reddy, C. Lakshmi Narayana Reddy, V. N. Myreddy, and S. Jayarama Reddy, "Electrochemical reduction of flutamide and its determination in dosage forms and biological media," Journal of Clinical Medicine and Research, vol. 3, pp. 35-39, 2011.

[11] E. Hammam, H. S. El-Desoky, K. Y. El-Baradie, and A. M. Beltagi, "Three validated stripping voltammetric procedures for determination of the anti-prostate cancer drug flutamide in tablets and human serum at a mercury electrode," Canadian Journal of Chemistry, vol. 82, no. 9, pp. 1386-1392, 2004.

[12] A. A. Smith, R. Manavalan, K. Kannan, and N. Rajendiran, "Spectrofluorimetric determination of flutamide in pharmaceutical preparations," Oriental Journal of Chemistry, vol. 24, no. 1, pp. 189-194, 2008.

[13] P. Nagaraja, H. S. Yathirajan, H. R. Arun Kumar, and R. A. Vasantha, "Spectrophotometric methods for the determination of flutamide in tablets," Indian Journal of Pharmaceutical Sciences, vol. 64, no. 3, pp. 272-274, 2002.

[14] K. S. Rangappa, P. Nagaraja, and K. C. S. Murthy, "New extractive spectrophotometric determination of flutamide in pure and pharmaceutical formulations," Analytical Sciences, vol. 16, no. 6, pp. 637-639, 2000. 
[15] K. M. Reddy, K. Suvardhan, K. Suresh, S. Prabhakar, and P. Chiranjeevi, "New spectrophotometric method for the determination of flutamide in pharmaceutical preparation using chromotropic acid as a coupling agent," in Proceedings of the 3rd International Conference on Environment and Health, pp. 410-416, Chennai, India, December 2003.

[16] "Validation of analytical procedures: text and methodology Q2(R 1)," in Proceedings of the International Conference on Harmonization of Technical Requirements for Registration of Pharmaceuticals for Human Use, ICH Harmonised Tripartite Guideline, London, UK, November 1996. 


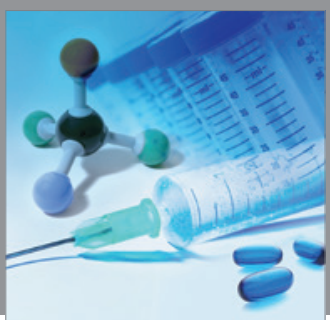

International Journal of

Medicinal Chemistry

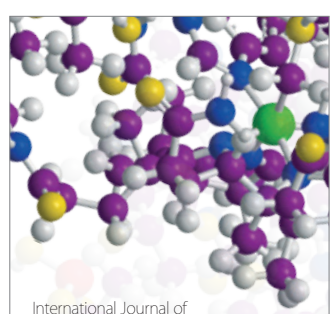

Carbohydrate Chemistry

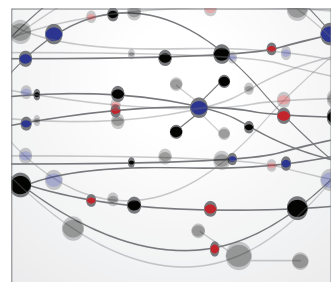

The Scientific World Journal
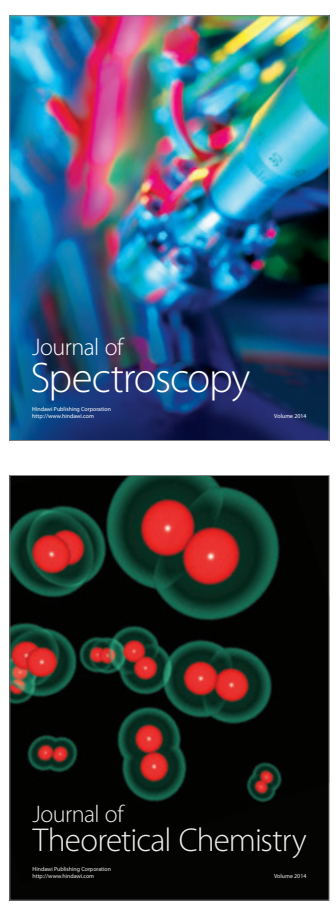
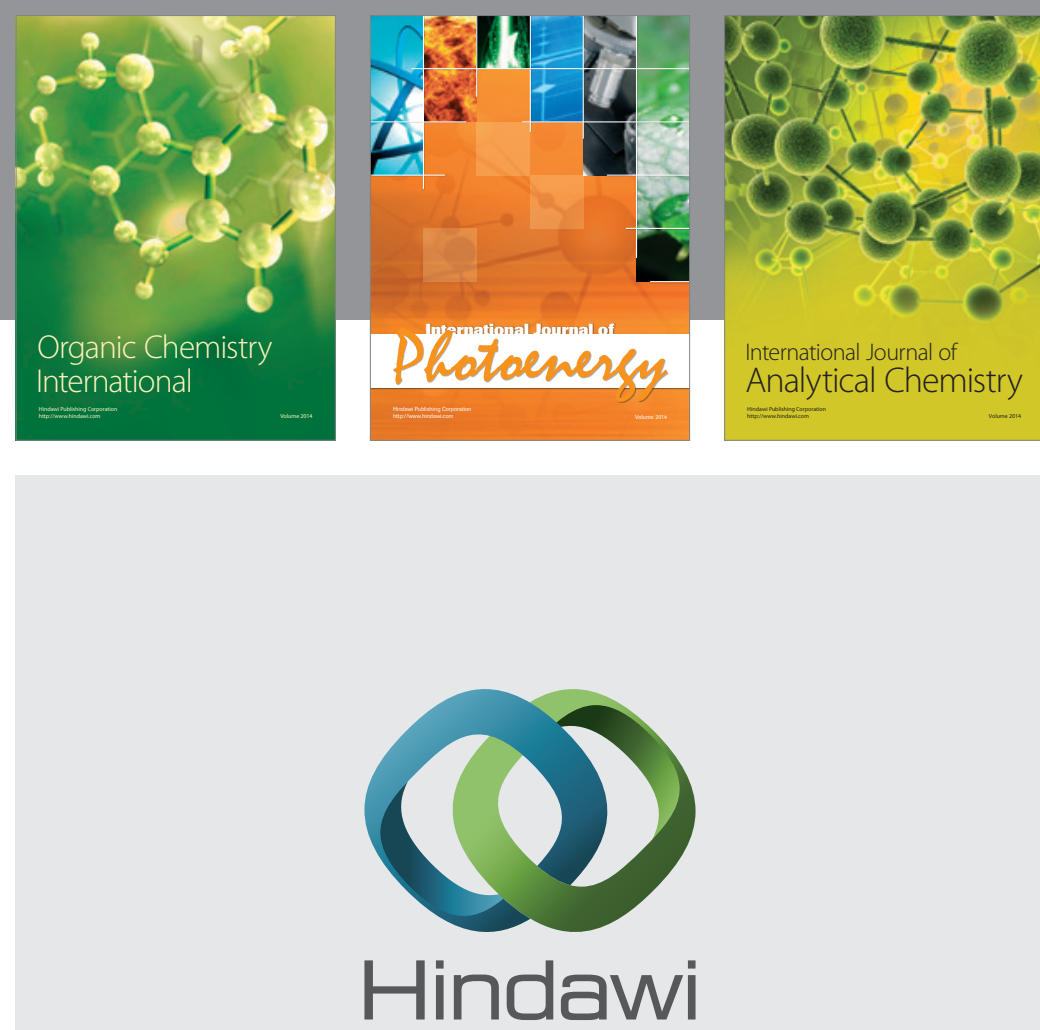

Submit your manuscripts at

http://www.hindawi.com
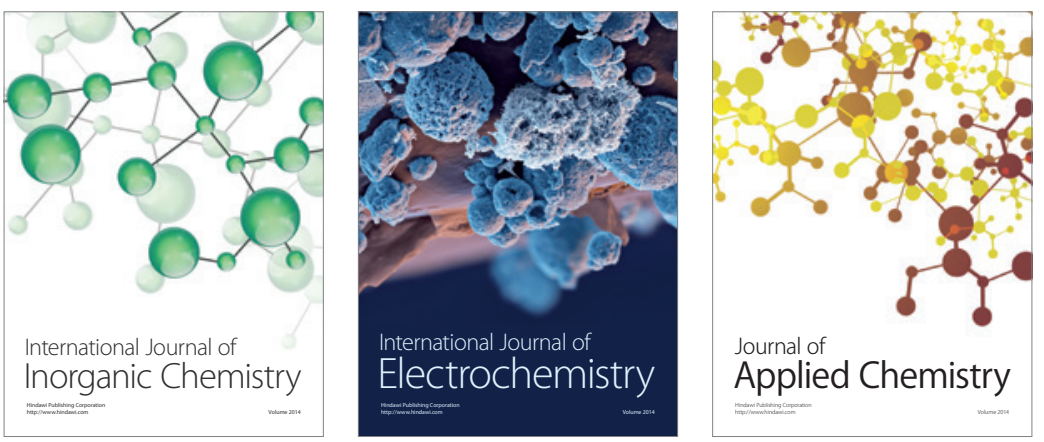

Journal of

Applied Chemistry
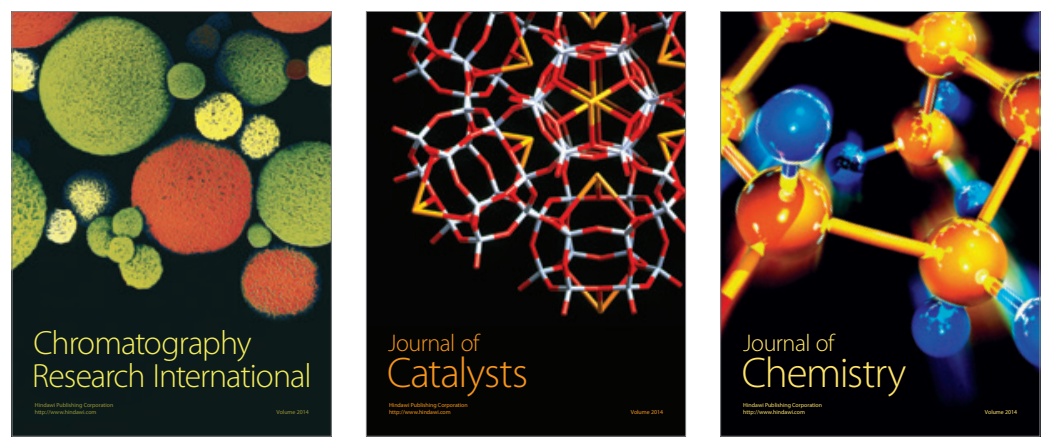
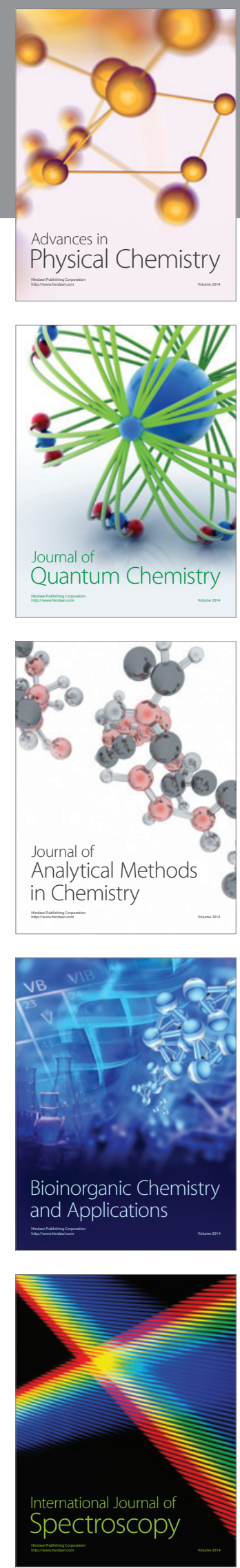